\title{
Relay nozzles and weaving reed
}

\author{
Karel Adamek $^{1}$, Petr Karel ${ }^{1}$, Jan Kolar ${ }^{1}$, Slavomir Jirku ${ }^{2}$, Vaclav Kopecky ${ }^{3}$, Jaroslav Pelant ${ }^{4}$ \\ ${ }^{1}$ VUTS - Centre of Machinery Research, Liberec, Czech Rep \\ ${ }^{2}$ CVUT - Czech Technical University, Faculty of Electrotechnics, Praha, Czech Rep \\ ${ }^{3}$ TUL - Technical University in Liberec, Faculty of Mechatronics, Liberec, Czech Rep \\ ${ }^{4}$ VZLU - Aeronautical Research and Testing Institute, Praha, Czech Rep
}

\section{Email address:}

karel.adamek@ vuts.cz (K. Adamek), jirku@fel.cz (S. Jirku), petr.karel@ vuts.cz (P. Karel), vasek.kopecky@tul.cz (V. Kopecky), pelant@vzlu.cz (J. Pelant)

\section{To cite this article:}

Karel Adamek, Petr Karel, Jan Kolar, Slavomir Jirku, Vaclav Kopecky, Jaroslav Pelant. Relay Nozzles and Weaving Reed. International Journal of Mechanical Engineering and Applications. Special Issue: Moving Forward to Monitory Democracy: Citizens Engagement in Scrutinizing Election Process in Indonesian 2014 General Election. Vol. 3, No. 1-1, 2015, pp. 13-21. doi: 10.11648/j.ijmea.s.2015030101.13

\begin{abstract}
The contribution describes the results of numerical flow simulations and experiments with so called auxiliary (relay) nozzles, used on powerful air jet weaving looms, further with complicated air flows interactions with the complicated reed wall, observing the nozzle setting toward the reed wall, the manufacturing of elements of the reed.
\end{abstract}

Keywords: Numerical Flow Simulation, Relay Nozzle, Weaving Reed

\section{Introduction}

The propagation of free air flow from the nozzle mouth is given by the theory of free flows [1], etc. The free flow velocity is decreasing by flow interaction with the surroundings, but the air velocity for transport of weft yarn should be necessary to keep at the required value along the whole weaving width of the loom. Therefore, the system of auxiliary nozzles is used today, after the style of their operation called also as relay nozzles.

The substantial disadvantage of the former standard design of such nozzles was the dependence of the air flow direction from the nozzle mouth on the value of supply pressure. The phenomenon was verified by visualization, measuring and real operation, too. In such a way, the initial optimal nozzle setting was changed, nevertheless, the change of the set pressure value is the basic kind of individual nozzle power regulation.

The following text describes the design and arrangement of typical nozzle kinds, regarding the directional stability of air flow from the nozzle mouth.

\section{Relay Nozzles}

\subsection{Standard One-Hole Nozzle}

Fig. 2-1 presents the velocity field of the standard design of auxiliary nozzle - in the side wall, there is created relative large outlet, typically as $\mathrm{L} / \mathrm{d}=0.5 / 1.5$, where $\mathrm{L}$ is wall thickness and $d$ is outlet diameter. The expressive flow separation in sharp flow bend of about $90^{\circ}$, together with flow separation from the opposite outer wall of the channel is the reason of decreased flow coefficient of such a nozzle. And more, the flow direction is changing with the value of the inlet pressure, see below Fig. 2-7, left column.

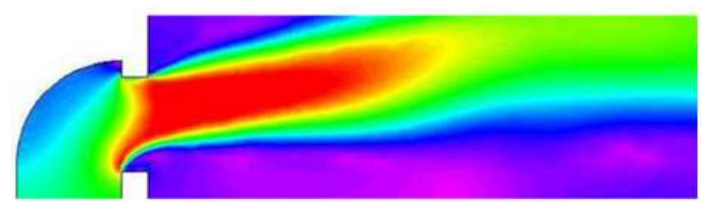

Figure 2-1. Isolines of Mach number, standard one- hole nozzle

Such phenomenon is not suitable for practical operation because in such a way the optimum assembling setting is changed. It is necessary to keep the most uniform and precise outlet diameter and wall thickness.

\subsection{Double Wall Thickness}

The next Fig. 2-2 shows the theoretical solution of double wall thickness where the outgoing air flow is better guided. From an operational trial it is known that a very small change of the wall thickness (for instance between 0.4 and $0.5 \mathrm{~mm}$ at the outlet diameter of $1.5 \mathrm{~mm}$ ) has an important influence on 
the outlet flow stability when the inlet air pressure is changed.

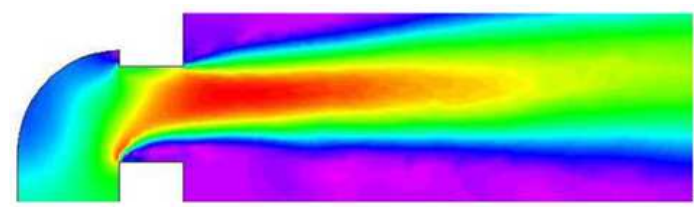

Figure 2-2. Isolines of Mach number, one- hole nozzle of double wall thickness

The design is not suitable for real operation due to a larger outline thickness of such a design of the nozzle body.

\subsection{Multi-Hole Nozzle}

Fig. 2-3 presents the well-known principle of the so called multi-hole (shower) nozzle after a Dutch patent from 1966, where the outlet mouth is designed as a system of small outlets typically $\mathrm{L} / \mathrm{d}=0.5 / 0.4$. The flow in such a mouth is well guided and its direction remains constant, regardless of the inlet pressure. Shortly after the outlet plane, the individual small jets are connecting together and continuing as one common free flow, subsequently fading. And more, the noise level of such a flow from several small orifices is much smaller, comparing with one outlet of the same cross section.

The design is suitable for real operation.

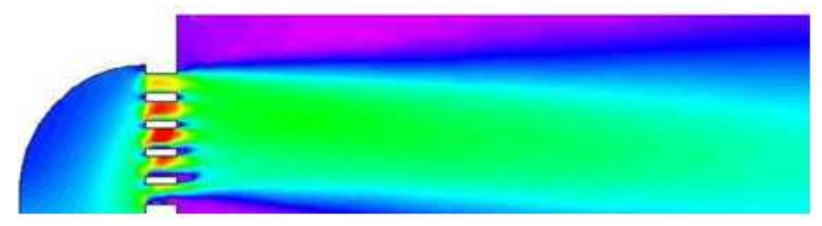

Figure 2-3. Isolines of Mach number, standard multi- hole nozzle

\subsection{Channel Nozzle}

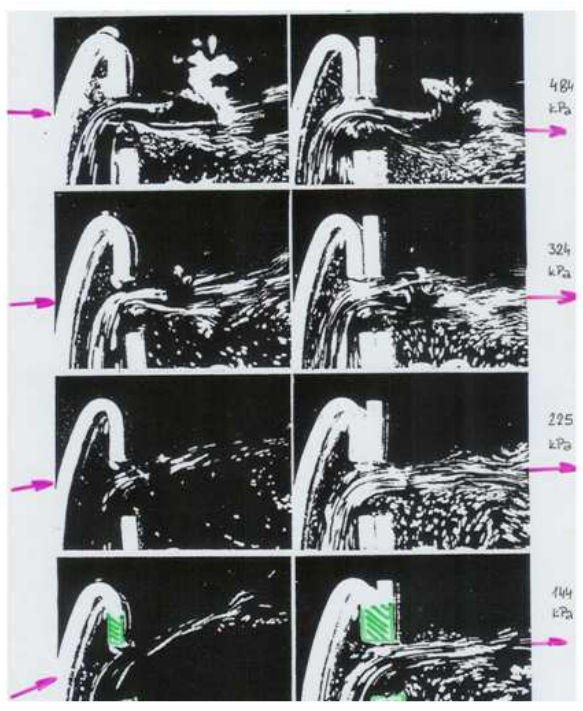

Figure 2-4. Hydraulic analogy of the flow Left column - standard nozzle, right column - double wall thickness

The idea appears after previous flow visualization in hydraulic bath [2], [3] - that it should be suitable to design the shape of the inner channel after the real shape of the flow field from hydraulic analogy.

The set of pictures in Fig. 2-4 presents the streamlines in hydraulic models of two nozzle designs - with simple and double wall thickness - for several pressure gradients. It should be to remark here that the used method of hydraulic analogy is valid for the flow of hypothetic gas (adiabatic exponent of $\kappa=2$ ) in thin layer above the bath bottom, only [4]. But in the time period „before computers“, there was not any other possibility how to study the processes inside nozzles. Nevertheless, the received qualitative results, only, were a good gain for the next progress of the solution.

The hypothesis was subsequently verified by measuring on the function model of such a channel of simple shape. In Fig. $2-5$, there is visible that for a certain outlet length of the channel outlet part, the flow direction remains the same, regardless the inlet air pressure.

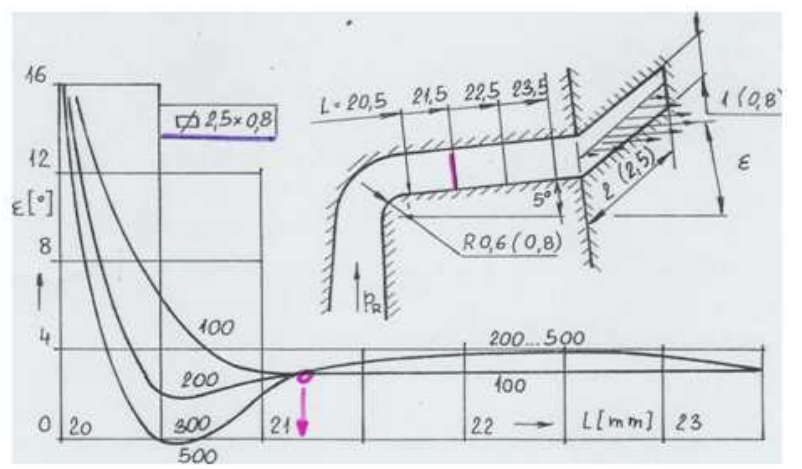

Figure 2-5. Flow direction from nozzle as function of the inlet pressure and length of outlet channel

Fig. 2-6 presents the geometry of a new type of so-called channel nozzle, designed with fluent transition between inlet and outlet to prevent the flow separation in the channel bend. The channel shape was designed after the condition of consecutive velocity increasing along the inner wall of the channel - it is the necessary condition preventing the flow separation [2], [5]. The outer shape of the channel is prescribed by the build-up volume of nozzle body for real operational application. On the detail of the flow field, it is visible that velocity value along the inner side of the channel does not decrease and the cross profile in the outlet cross-section is practically constant. Just before the nozzle outlet, it is evident a slight velocity decreasing, but practical trials confirm that such a small deviation from the pure theory has not any important influence on the direction of the free flow from the nozzle.

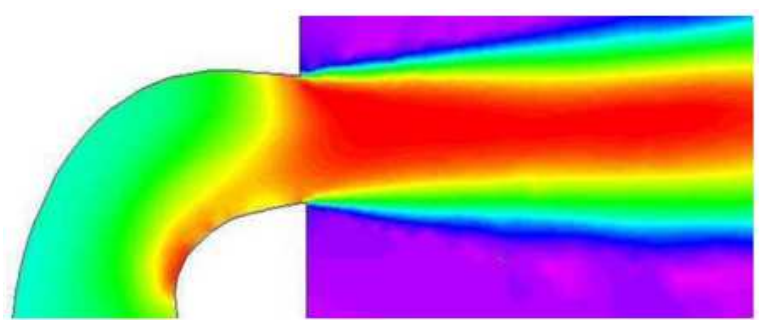

Figure 2-6. Isolines of Mach number, channel relay nozzle 
As an interesting thing, it should be to remark here that the method was initially developed and used for flow calculation of duct elbow between axial steam turbine outlet and condenser inlet for nuclear bloc of electric power output 1050 MW, it means of the condenser thermal output by estimation over $2000 \mathrm{MW}$ and here it was successfully used for channel nozzle of the output few watts, only.

The final operational verification was realized with a set of 100 manufactured nozzles [6], [7], [8], [9], [10], [11] - the flow direction remains constant regardless on the input pressure and the same for all tested nozzles.
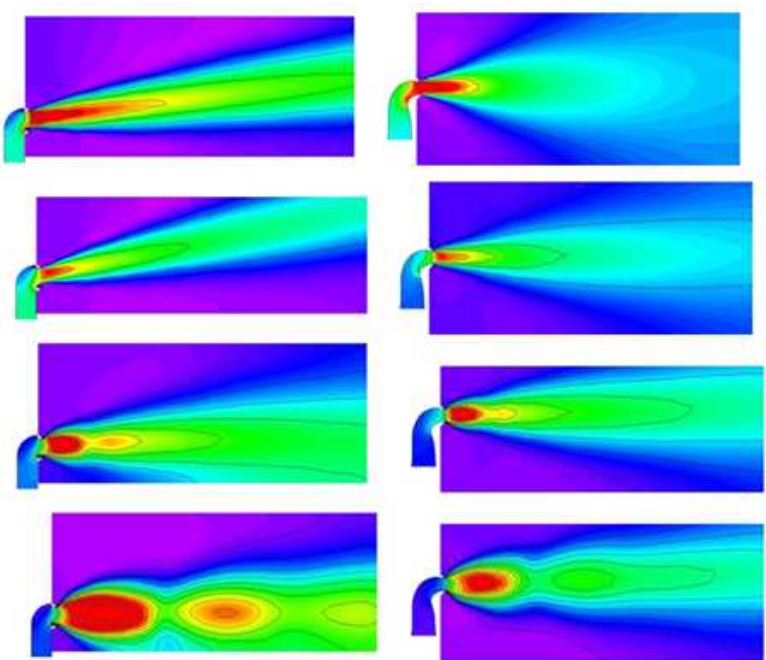

Figure 2-7. Isolines of Mach number, changes of the flow direction for various nozzles- pressure ratios of 0.7-0.4-0.2-0.1 (rows down from top) standard nozzle (left column), channel nozzle (right column)

The results of the hydraulic analogy in Fig. 2-4 were later verified by numerical simulation, see Fig. 2-7 for standard nozzle (left column) and for channel nozzle (right column), both for several pressure gradients $(0.7-0.4-0.2-0.1$ in rows). Together with decreasing pressure ratios, the image of shock waves is more expressive. With regard to the above mentioned illustrations of individual nozzle types, it is clear that the air flow separation just before the nozzle mouth has the greatest influence on the dependence of the free flow direction on the pressure gradient and that making suitable shape adaptations it is possible to get the free flow of constant direction. Due to large extent of used pressure ratios and velocity values, the color scale is not the same for all the solved cases.

\section{Braking Nozzle}

The standard problem of the air jet weaving is to accelerate the processed weft material at the necessary average picking velocity. But when very heavy materials are processed, then arises the inverse problem: after the picking of measured weft length it is necessary to stop the flying and very heavy weft yarns during the time of 2-3 milliseconds. Thereby arise in the weft material very high tensile strengths due to inertial forces, which can lead to the destruction of elementary fibers in the yarn. The unsuitable consequence of it is a different appearance of the fabric in the points of destructions. The problem was detected by the weaving of glass wall covers of weft mass till $600 \mathrm{~g} / \mathrm{km}$ at a weaving width of $1.9 \mathrm{~m}$ and at 550 rpm. For comparison: the weft mass of classical blue denim, in standard assortment considered as heavy material, reaches of $100 \mathrm{~g} / \mathrm{km}$, only.

Using a simple model of the free air flow [1, the flow field of several relay nozzles in the reed channel was defined, see Fig. 3-1 and consequently the force effects of such flows on the weft yarn as a transported linear and very flexible body were defined, too. The system of solved equations of movement then describes the movement of one-dimensional flexible continuum in the air flow and the strengths, arising during its rush stop [12].

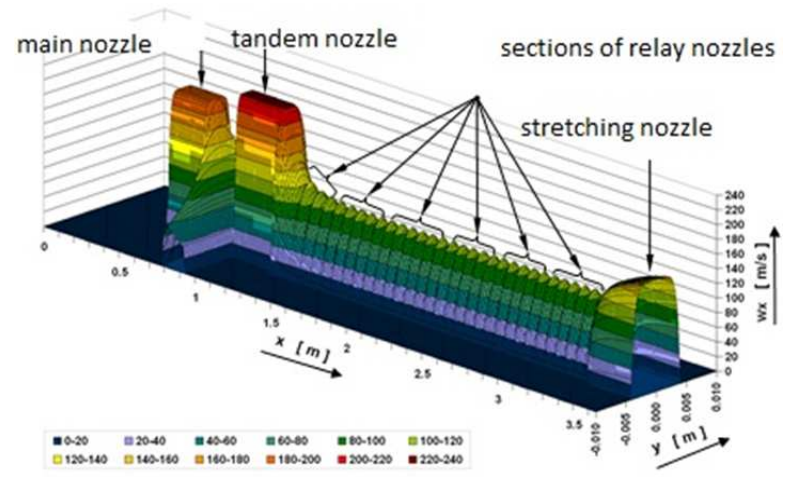

Figure 3-1. Calculation scheme of the velocity field in reed channel

The main result of the work is as follows: the decreasing of the tensile forces during the rush stop it is possible to get by short braking (some milliseconds, only) of the whole flying weft length just before the arriving the weft tip into the final position. To verify and realize this hypothesis, the function model of such a braking nozzle was realized and experimentally verified, see Fig. 3-2, made from the same semi-product as a standard relay nozzle above [13], [14], [15], and [16].

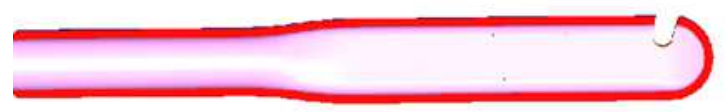

Figure 3-2. Scheme of the braking nozzle

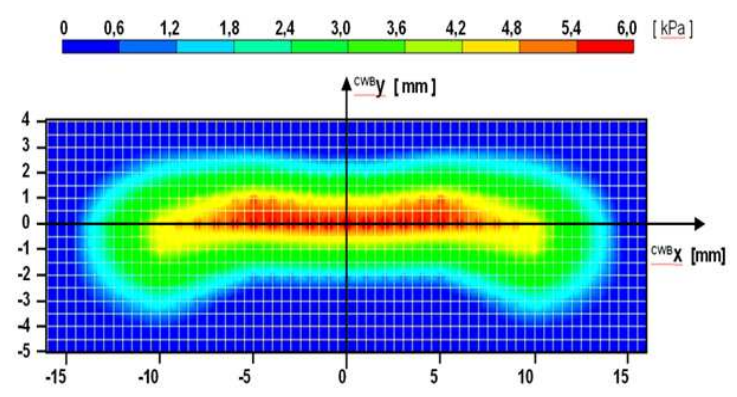

Figure 3-3. Cross-section of the velocity field from braking nozzle at distance of $13 \mathrm{~mm}$ from the nozzle mouth 
The suitable mouth shape ensures that in a small distance from the mouth of such a braking nozzle the cross-section of such air flow is very flat oblong after Fig. 3-3 (here 6x30 mm approx.), herewith in the reed channel it is fed the maximum of the air from the nozzle so that the exploitation of its energy for braking is very high

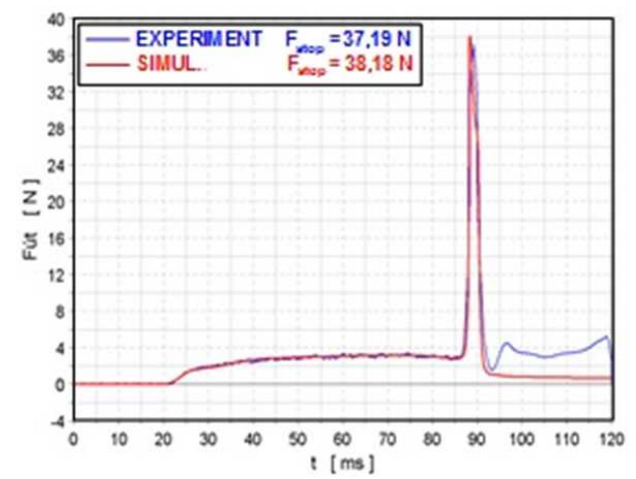

Figure 3-4. Original pick value of tensile force in the weft yarn

Practical verification after [13], [14] is illustrated in Fig. 2-4 - the pick value of tensile force is decreased due to the application of braking nozzles at $2 / 3$ approx. of the original value.

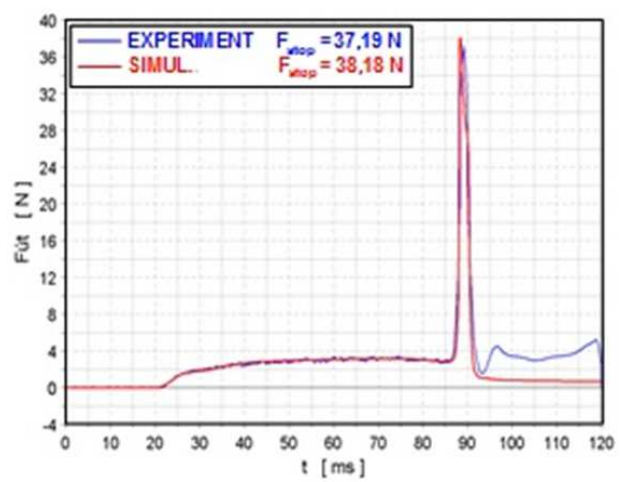

Figure 3-5. Decreased pick value of tensile force in the weft yarn, applying braking nozzles

\section{Weaving Reed}

The weaving reed is used on weaving looms for the fabric creation by the beat-up effect on each just picked weft yarn. The reed consists from thin metallic plates (dents), separated by gaps for guiding warp yarns. On air jet looms, the reed receives the next important function more - its special U-shaped and permeable channel partially inhibits the natural fading of the air flow in the surroundings, to keep the transporting effect of the air flow at a relative high value.

For a studying of very complicated interactions of air flows with the complicated shape of the reed channel with partially permeable walls, numerical models are used. Here are presented some solved cases.

\subsection{Aperiodic Case}

Typical aperiodic two-dimensional (2D) solution was used in the study of the flow transition from the main nozzle into the reed channel [17], [18], here without the following effect of auxiliary nozzles. Fig. 4-1 presents the velocity field of a standard solution with strong stream in the reed channel. The channel walls prevent the flow dissipation into the surroundings, their amplifying effect is not negligible verified by LDA measuring and by real weaving trials, too.

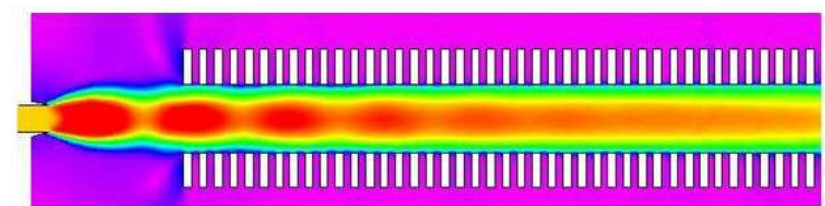

Figure 4-1. Original design, velocity isolines

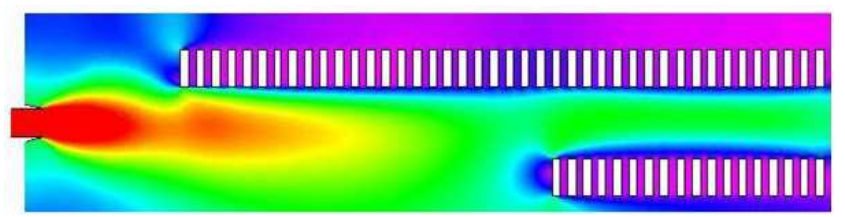

Figure 4-2. Removed dents, velocity isolines

The following Fig. 4-2 shows the situation when several first dents were removed from any design reasons. The flow without side guiding is expressively deflected out from the channel axis, thus the velocity in the channel is decreasing and the reliability of the weft picking is decreasing, too.

The last Fig. 1-3 presents one of the possible remedy of the previous unsuitable state by slight inclination of the nozzle axis in the direction to the intact wall of the weaving channel. The velocity in the channel is increasing again to the value similar to the original case.

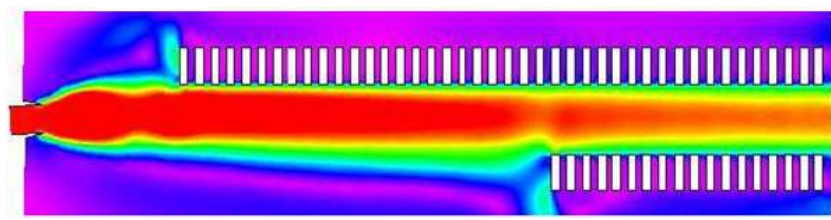

Figure 4-3. Modified nozzle inclination, velocity isolines

\subsection{Periodic Case}

For better image it is not presented here the main nozzle influence at the reed beginning (left side), but the influences of relay nozzles, only.

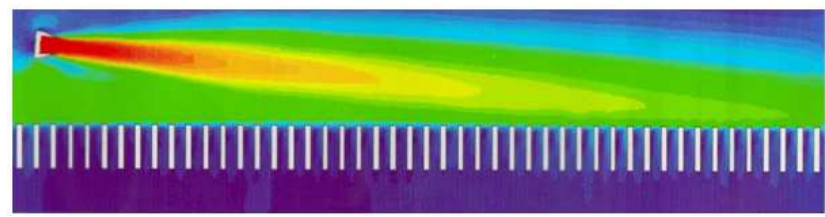

Figure 4-4. Interaction between flow from nozzle outlet and reed wall, velocity isolines

In Fig. 4-4, we can see the complicated flow field due to the interaction of the flow from the relay nozzle with the wall of the reed, which consists from crosswise oriented metallic dents separated by gaps. The flow from the nozzle outlet 
impacts the individual dent of the reed under different velocity - both value and direction - depending on the relevant dent distance from the nozzle outlet. The results of Par. 5 should be corrected in this sense.

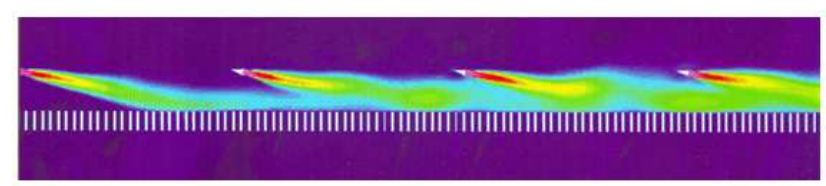

Figure 4-5. Interaction of flows from relay nozzles mutually and with the reed wall, velocity isolines

In addition, the next Fig. 4-5 represents mutual interactions of flows from several such nozzles, situated along the reed wall. It is visible that the fading flow from the previous nozzle amplifies a little the flow in the area of the next nozzle. Some part of the air volume is flowing out from the area of weft movement (picking) into the surroundings, either directly by the reflection from the reed wall (up) or by passage through gaps among individual reed dents (down). With an increasing number of nozzles, the medium velocity is increasing a little, too, after some number of nozzles, the balance between air inlet from nozzles and flow dissipation into surroundings is reached - see experiment in Par. 6.

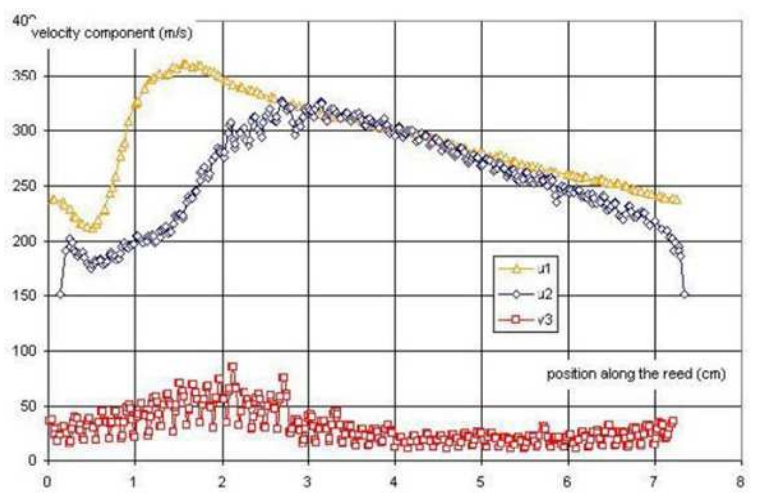

Figure 4-6. Profiles of velocity components along the reed wall from the Fig. 4-4

The relevant profiles of velocity components in the cross-section along the inlet side of the reed wall are presented in the next Graph in Fig. 4-6. The lengthwise component, evaluated at the distance of $3 \mathrm{~mm}$ from the reed wall (yellow, signed as $\mathrm{u} 1$ ), has a typical wavy character, according to the experiment, given by the flow fading from the previous nozzle pitch and following flow amplification from the nozzle situated at the beginning of the monitored pitch. The same component, evaluated just at the reed wall (blue, signed as $\mathrm{u} 2$ ), has its value at the point of the maximum influence of the nozzle flow and more, there is visible some variation, given by the effects of individual reed dents and their gaps. The cross component (signed as v3) is many times smaller and represents the flow escape among the dents. The highest variances are in the area of the maximum effect of the nozzle flow where the lengthways component is the highest.

Compared with the experiment, in the right side of the profile there is a smaller velocity decreasing. It should be the mistake given by the used two-dimensional (2D) model instead of the three-dimensional (3D) reality.

\section{Influence of Reed Dent Shape}

Several design parameters influence the flow field along the reed wall, its partial penetration through the wall and reflection from the wall: the reed wall filling or density of dents, the shape of individual dents (edges chamfering), etc. [20]. For better imagination and possibility of a next analysis, the individual effects were solved separately as 2D models of individual dents. Using the periodic boundary condition on both left and right sides of the solved area, the solution time is very short, the received results correspond to the flow around general one dent in the dent row, creating the reed wall. The influence of the flow angle of attack was modeled as a velocity vector at the inlet side of the solved area.

Really, the angle of attack is different for each dent in the row, depending on the distance from the relay nozzle outlet (see above).

\subsection{Dents Arrangements}

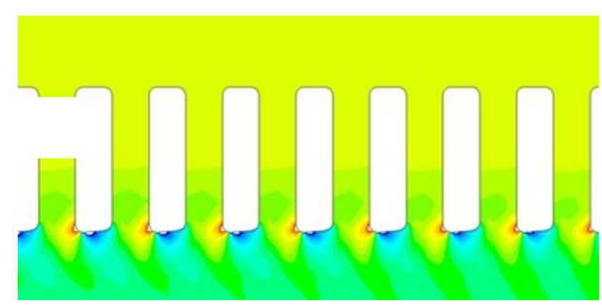

Figure 5-1. Pressure field - the maximum in the stagnation point at the leading edge, the point of the maximum erosion

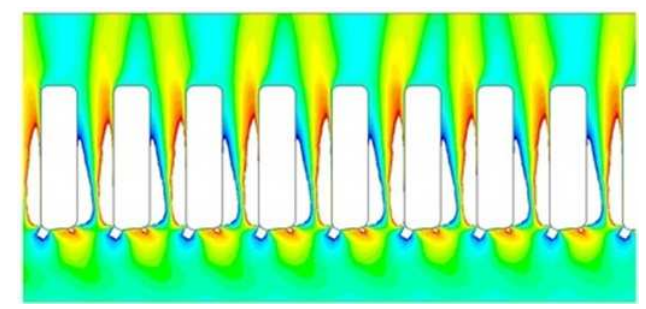

Figure 5-2. Velocity field - periodic shape on the inlet side with interesting but for weaving not usable flow bends at the outlet side

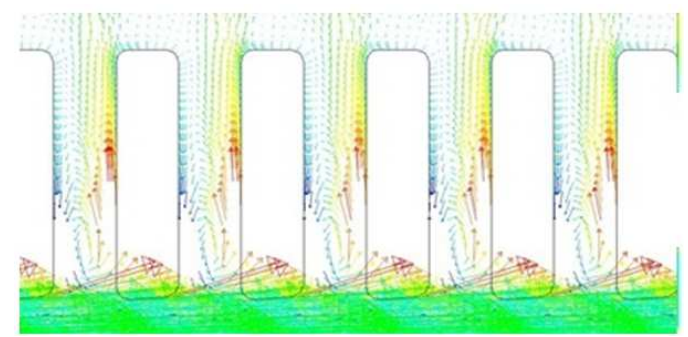

Figure 5-3. Directional field with recirculation vortex on trailing (leeward) edges of individual dents

Several cases were solved for different shapes and arrangements of dents, as an illustration, only, Fig. 5-1 to Fig. 5-3 present the pressure, velocity and directional fields of one 
solved case. The air inlet is defined identically, as a value of $100 \mathrm{~m} / \mathrm{s}$ and inclined $5^{\circ}$ up from the lower horizontal boundary, on the lower side from the left.

\subsection{Reed Wall Filling}

The next serial of results in Fig. 5-4 presents the influence of various combinations of wall filling (reed dent thickness = $0.6 / 1.6$ as thin and 1.0/1.6 as dense) and of several shapes of edges (rectangular, rounded, chamfered). The air inlet is defined up from the left side, $100 \mathrm{~m} / \mathrm{s}$, inclination of $5^{\circ}$ down from the horizontal direction.

It is well visible that each such detail changes expressively the global flow field. Theoretically very interesting, but for real weaving process unusable is the area of a partial flows superposition behind the reed wall.

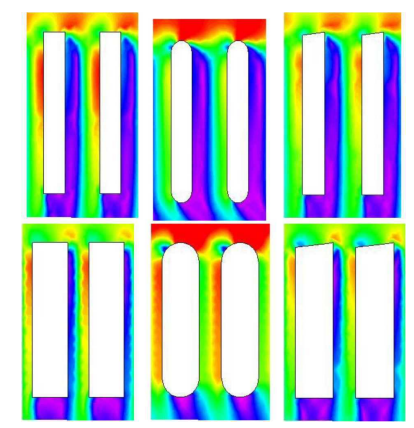

Figure 5-4. Velocity field for various design cases of reed walls, row $1=$ filling 0.6/1.6,row 2 = filling 1.0/1.6, columns for various shape of edges

From the received results it is possible to evaluate for instance the lengthwise component of air velocity, which has the main influence on the weft yarn transport along the reed wall or the crosswise component of air velocity, which can characterize the permeability or reflectivity of the reed wall for the air. The practical consequence is as follows: The flying weft yarn must be hold nearby the reed wall in some instable balance - the weft yarn must not be pushed out from the reed wall in order not to fly out from the weaving channel and must not be too much pressed to the wall in order not to increase the friction along the reed wall.

The presented method allows answer many questions before the designing and manufacturing of a new kind of the reed, for instance:

- For weaving of very heavy technical cloths it should be proposed a suitable reed dents density (warp pitch), the value is outside all standard recommendations for standard clothes.

- The dents are ground after cutting; during this process, different edge rounding at different points of the dent perimeter increases, which have different influences on the resulting aerodynamic behavior of the reed channel.

- Even at the channel bottom, the grinding is very imperfect, the cutting edge remains coarse and chamfered after the shear. Such dents can be used for one direction of picking, only, the chamfered edge must have a confusing character - otherwise, the air flow is fading out through the reed wall and the tensile effect of the flow is negligible.

- When weaving aggressive materials (glass), the edges of dents are eroded very quickly, therefore, they receive a typical chamfered shape. Thereby the aerodynamic characteristics of the channel is changed, it should be reground or exchanged the dents or to use a material more resistant. After Fig. 5-5, the maximum erosion comes in the area of the stagnation point on the upper leading edge of dents, where the flow along the reed wall is locally stopped. On the right side, there is the deformed pressure field around the eroded dents.

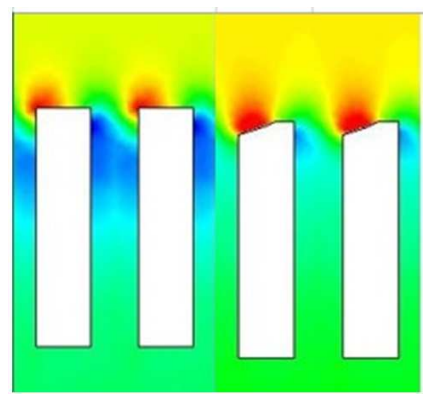

Figure 5-5. Pressure field on new dents (left) and eroded dents (right)

\section{Experiment}

Fig. 6-1 presents the record of dynamic pressure in the weaving channel, together $5 \times 5$ points in cross-sections each $10 \mathrm{~mm}$ (nozzle pitch of $80 \mathrm{~mm}$ ), the first section $(x=0)$ is coincident with nozzle position.

$\mathrm{x}=0$ - fading influence of the previous nozzle, the maximum of the measured profile is situated inside the channel up, it is decreasing in the directions down and out

$\mathrm{x}=10,20$ - the same, but values are smaller at a longer distance from the outlet of the previous nozzle

$x=30-$ in the outer lower corner it begins the effect of the nozzle situated at the position of $\mathrm{x}=0$ and down and out relative to the channel

$x=40,50-$ the nozzle influence is markedly stronger, the maximum value is increasing and all the profile is filling in general

$x=60-$ the full profile in the whole channel cross-section

$x=70-$ the nozzle influence in the inner upper part of the channel is increasing yet, but in the lower outer part becomes too weak

$\mathrm{x}=80$ - identical with $\mathrm{x}=0$, the trend identical with $\mathrm{x}=$ 70 , the maximum is reached in the upper inner part, but in the lower part weak yet.

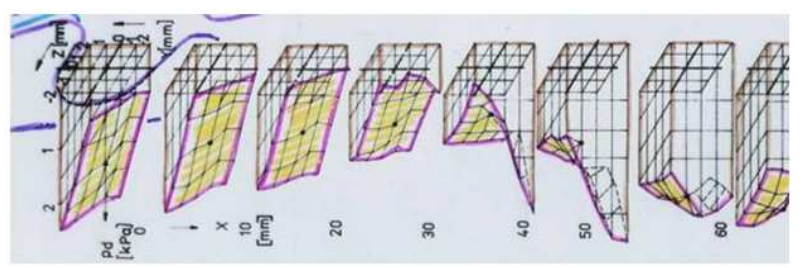

Figure 6-1. Profiles of dynamic pressure in the reed channel

The above mentioned simulated flows from the adjoining 
auxiliary nozzles were verified by laser anemometer measurements (LDA) [3], [19], [20], [21], [22]. The curve 1 in Fig. 6-2 shows that such a steady state was reached after the 4 th or the 5th nozzle. For better transparency, the influence of the main nozzle is here omitted again. Further, it is visible that nozzle No. 8 is feebler, maybe clogged or set at a wrong position toward the channel. The lower curve 2 presents the velocity profile along the same measuring axis, but without the reed. The difference between both curves (highlighted in yellow) is the amplifying effect of the reed channel.

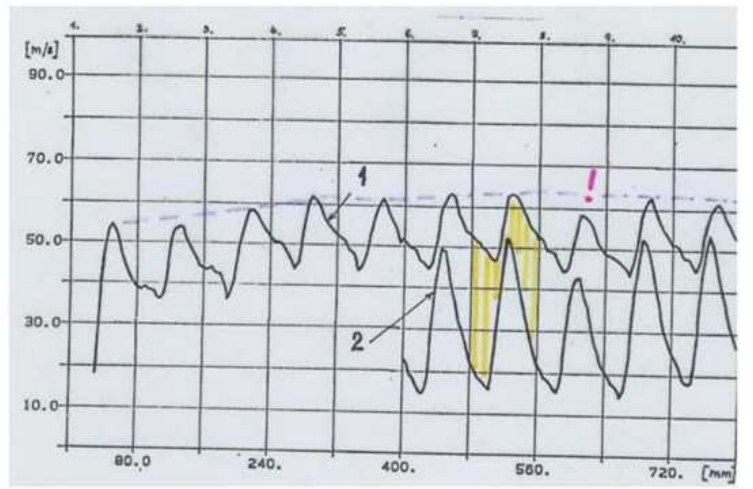

Figure 6-2. Velocity profile along the reed channel axis (1= operational setting with reed, 2 = without reed)

The next Fig. 6-3 shows that a considerable part of the flow from the nozzle outlet does not get the reed channel at all. This action is here presented as an intersection of such conical air flow with the cylindrical reed channel of U-shaped base. Velocities in individual points of the conical flow are well-known, described by empirical formulas, for instance in [1] and others. In the given configuration, it penetrates in the channel the red highlighted part, only. The resulting percentage from the air volume from the nozzle outlet reaches a maximum of $26 \%$. Such a simplified calculation does not think the real reflectivity of the reed wall, therefore, the reality is a little better.

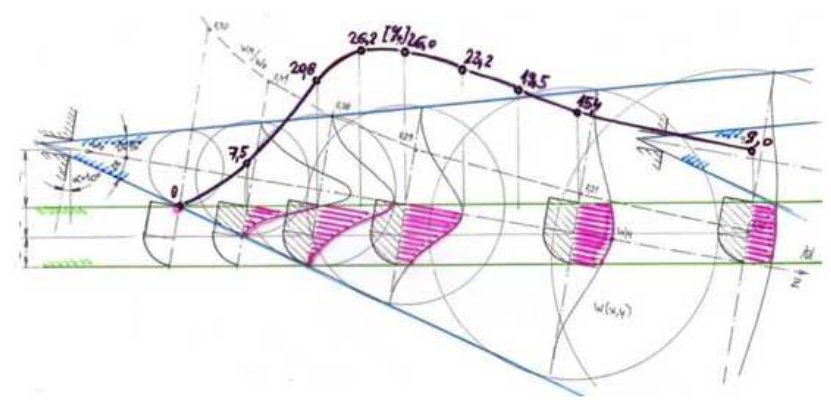

Figure 6-3. Theoretical intersection of conical flow from nozzle outlet with reed channel

Very important is the right setting of the whole set of nozzles on the loom, too [23], [24], [25], [26]. All relay nozzles installed on the loom are set in such a manner that the axis of all free flows along the weaving channel axis were set in an optimum direction. In Fig. 6-4, we can see the measured values of dynamic pressure without adjusting (lower curve). It is evident that after adjusting of all relay nozzles after mounting a template (upper curve), the average value of dynamic pressure is increasing nearly twice and the standard deviation is decreasing on one quarter, only.

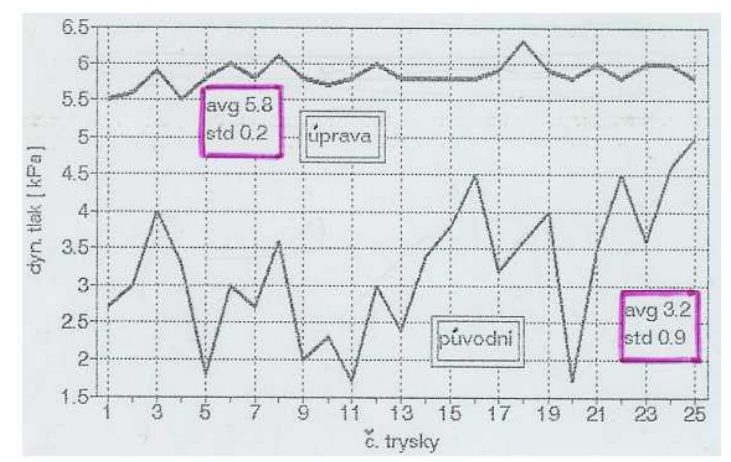

Figure 6-4. Dynamic pressure values (Pa) of relay nozzles (No. 1-25) on the loom - mounted only (down) and adjusted (up)

\section{Three-Dimensional Model}

The first simple model [27], [28] has solved the flow range from the nozzle outlet and spreading along the reed channel shaped after Fig. 7-1: cross section (up) with simplified shape, highlighted relay nozzle outlet position, in lengthwise section (down) it is visible the used reed filling of $50 \%$.

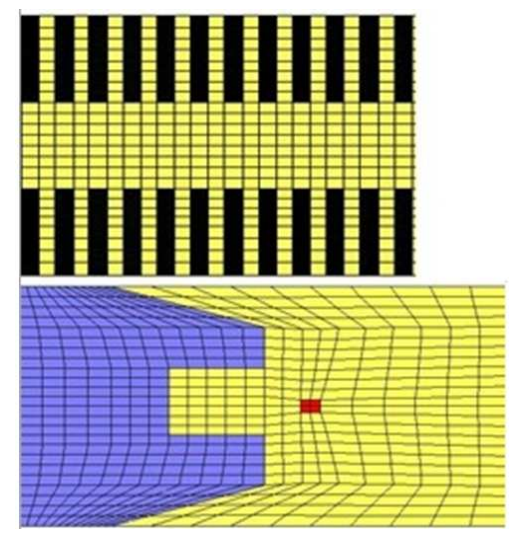

Figure 7-1. Scheme of solved channel with nozzle outlet-cross-section (up) with highlighted relay nozzle position and lengthwise section (down)

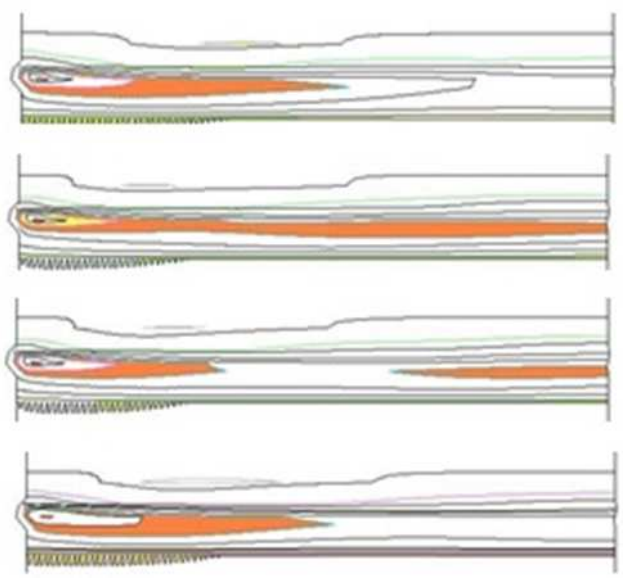

Figure 7-2. Velocity field in the channel-several time points 
Several corresponding cross-sections of velocity field in different time points are in Fig. 7-2, with a highlighted area of critical velocity. It is clear that this field is time-depending, developing, interrupting and developing again. But in the reality, such a long field does not exist (both in time and in distance) because the velocity field from the main nozzle, situated at the channel begin, is kept on the needed value by the system of relay nozzles along the channel length. The whole field periodically arises and ceases after each weft picking when the velocity field is fully destroyed by the warp yarns movements and arises again at the beginning of a new weft picking.

The next three-dimensional model [29] describes the complex flow interaction from the real nozzle with a real shape of reed channel, consisting from individual dents. One period is solved, limited by positions of two adjoining relay nozzles. From the next evaluation, it is possible to determine influences of several parameters on both average value and standard deviation of the flow field in the channel. The result is affected by the both nozzle design, see above, by the nozzle setting (angles of elevation, inclination, nozzle position towards the channel axis), nozzle pitch, the kind of the reed (dents density, edges chamfering), etc.

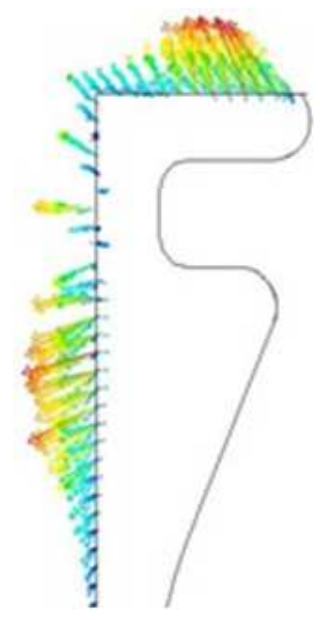

Figure 7-3. Directional field-air penetration through gaps between dents

In Fig. 7-3, there is the directional field of the flow penetrating through the gaps between dents, for real designed setting. The nozzle outlet is on the left side up.

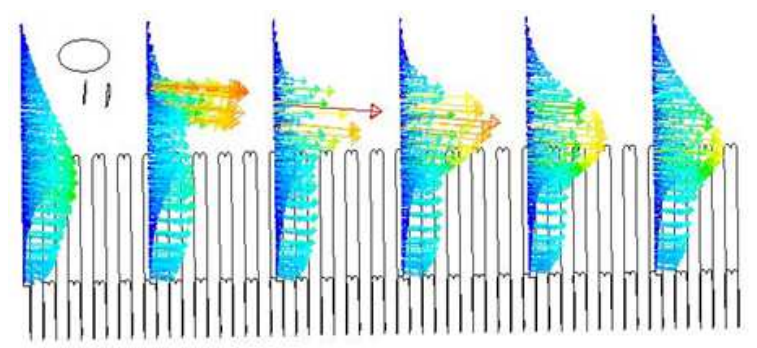

Figure 7-4. Directional field-driving component of air velocity

The next Fig. 7-4 shows the directional field in several cross-sections within one period between two adjoining relay nozzles - the driving component of air velocity and Fig. 7-5 shows the same field in front view - different values of the flow rate going through individual gaps.

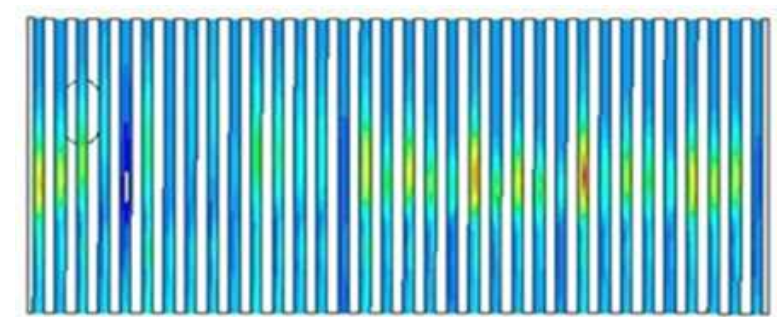

Figure 7-5. Velocity field - front view - air penetration through reed gaps

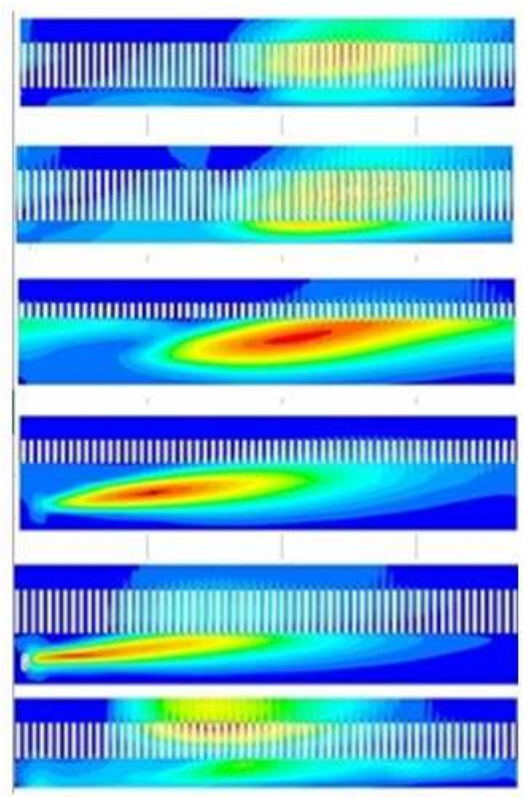

Figure 7-6. Serial of velocity fields in several horizontal sections

The serial of horizontal lengthwise sections in Fig. 7-6 presents the velocity field in several horizontal planes of the reed channel equipped by so-called shower nozzles (19 outlets of $0.4 \mathrm{~mm}$ diameter), situated from the left side down. The value of $\mathrm{y}=0 \mathrm{~mm}$ corresponds to the upper edge of the reed channel, the value of $y=-8.3 \mathrm{~mm}$ is the approx. position of the central outlet axis. Sections at levels of $+6,+2,-2,-6$, $-10,-14 \mathrm{~mm}$ were used with various scales in individual sections to get the maximum contrast of velocity fields in all sections.

\section{References}

[1] J. Chysky, V. Oppl, "Heating, ventilating, air conditioning", SNTL Praha 1973 (in Czech).

[2] K. Adamek, "Stafettendüsen hergestellt im Feingussverfahren, 6. Weberei Kolloquium, ITV Denkendorf, Germany, 1990.

[3] V. Kopecky, K. Adamek, "Using of LDA and hydraulic analogy in air jet weaving, 5th Int. Symp.on Flow Visualization V, 703-710, Hemisphere Publ. New York, 1990. Presented at the Flow Visualization V, VSZ Praha, 1989. ISBN 0-89116-887-7. 
[4] J. NoZiCka, "Analogous methods in flowing", Academia Praha, 1967 (in Czech).

[5] S. Jirku, "CAD of optimized channel shape for relay nozzle", Int. sci. conf. Applic of exp. and numer. meth. in fluid mech., p. 19-23. VSDS Zilina, 1991. ISBN 80-85404-04-4 (in Czech).

[6] K. Adamek, "Verification of the optimized channel shape for relay nozzle", Int. sci. conf. Applic of exp. and numer. meth. in fluid mech., p. 24-30. VSDS Zilina, 1991. ISBN 80-85404-04-4 (in Czech).

[7] K. Adamek, "Channel relay jets", Textile Technol. Int., 1993 (140-143), Sterling Publ. Ltd., London - Hong-Kong, ISSN 0953-2404.

[8] K. Adamek, "Channel relay jets", habilitation lecture, TU Liberec, 1992 (in Czech). Made in the collaboration with ABB Cerama Robertsfors / Sweden, 1991.

[9] K. Adamek, M. Bandouch, "Relay nozzle", Czech patent No. AO 266516, 1987.

[10] K. Adamek, "Channel relay jets", 6th Int. Conf. on the Theory of Machines and Mechanisms. TU Liberec, 1992 (in Czech).

[11] K. Adamek, "Nozzles made by exact casting process", Textile technics, vol. 1 (1988), EKVU+VSST+SVUT Liberec, 1988 (in Czech).

[12] P. Karel, " Dynamics of the weft movement in the final phase of weft picking on the air jet loom", PhD thesis, SF TU Liberec, 2006 (in Czech).

[13] K. Adamek, P. Karel, "Aerodynamic weft brake", XIIIth int. conf. Applic. of exp. and numer. meth. in fluid mech., $\mathrm{ZU}$ Zilina, 2002, p. 1202-107. ISBN 80-7100-955-5 (in Czech).

[14] K. Adamek, P. Karel, "Aerodynamic weft brake", Fluid Structure Interaction and Moving Boundary Problems IV, WIT Press, New Forest 2007. ISBN 978-1-84654-072-9.

[15] K. Adamek, "Aerodynamics of the continual weft brake", 24th int. conf. Quo vadis textrinum, NMC Zilina, Tatranska Lomnica, 2002. ISBN 80-8565-521-7 (in Czech).

[16] K. Adamek, P. Karel, "Aerodynamic weft brake", XIIIth. int. conf. Applic. of exp. and numer. meth. in fluid mech., ZU Zilina, Oravsky Biely Potok, 2002. ISBN 80-7100-955-5 (in Czech).
[17] K. Adamek, J. Pelant, "Air flow at the beginning of the reed channel", 4th Seminar Euler and Navier-Stokes Equations, Inst. of Thermomechanics, Czech Acad. of Sciences Prague, 2001, ISBN 80-85918-62-5.

[18] K. Adamek, "The flow field for yarn transport", XVth int. sci. conf. Applic. of exp. and numer. meth. in flow mech., $\mathrm{ZU}$ Zilina, 2006. ISBN 80-8070-533-x (in Czech).

[19] V. Kopecky, K. Adamek,"Velocity field in weaving channel of the air jet loom", Int. sci. conf. Applic. of exp. meth. in flow mech., CSVTS Zilina, Tatranske Matliare, 1989 (in Czech).

[20] K. Adamek, V. Kopecky, "Velocity field from the relay nozzle", Int. sci. conf. Applic. of exp. meth. in flow mech., CSVTS Zilina, Tatranske Matliare, 1989 (in Czech).

[21] V. Kopecky, K. Adamek, P. Stradal, "Measurement of free air jets in weaving machines", Xth Symp. on LDA, STU Bratislava, 1988.

[22] V. Kopecky, K. Adamek, "Using of LDA for velocity fields measuring", Vth int. conf. on theory of machines and mechanisms, VSST Liberec, 1988 (in Czech).

[23] K. Adamek, "Optimale Düseneinstellung an der Luftwebmaschine", 7. Chemnitzer Textilmaschinen-Tagung, TU Chemnitz, 1999. ISBN ...

[24] K. Adamek, "Weaving of flat wefts by air flow", Quo vadis textrinum, Carpatia Tour, Strbske Pleso, 1994 (in Czech).

[25] K. Adamek, "Optimum relay nozzle setting on air jet loom", 3rd Int. Conf. Novelties in weaving research and Technol., Univ. of Maribor, 1999, ISBN 86-435-0289-8R.

[26] K. Adamek, "Influence of nozzle position on air jet weaving", Textile technics, Vol. 2 (1990), VUTS + VSST Liberec (in Czech).

[27] J. Pelant, K. Adamek, "Air flow in picking channel of air jet loom", ECCOMAS 2000, Barcelona, ISBN-84-89925-69-0.

[28] J. Pelant, K. Adamek, "The range of the air flow in picking channel of air jet loom", report VUTS Liberec for Picanol, Ieper, Belgium, 1999, unpublished.

[29] J. Kolar, "Velocity field in picking channel", internal report VUTS Liberec for looms producer, unpublished. 